\title{
Bilateral ovarian cystic lymphangioma with chylous ascitis in pregnancy - a rare case report with review
}

\author{
Archana Daddenavar ${ }^{1}$, Vikas Daddenavar ${ }^{1}$, Rashmi Patil $^{2}$ \\ ${ }^{1}$ Daddenavar Hospital, Bagalkot, Karnataka, India \\ ${ }^{2}$ St Martha's Hospital, Bangalore, Karnataka, India \\ Received: 13 March 2016 \\ Revised: 10 April 2016 \\ Accepted: 14 April 2016 \\ *Correspondence: \\ Dr. Archana Daddenavar, \\ E-mail: drarchanavd@gmail.com \\ Copyright: ( $\odot$ the author(s), publisher and licensee Medip Academy. This is an open-access article distributed under \\ the terms of the Creative Commons Attribution Non-Commercial License, which permits unrestricted non-commercial \\ use, distribution, and reproduction in any medium, provided the original work is properly cited.
}

\begin{abstract}
Bilateral lymphangioma of the ovary being an extremely rare lesion, with chylous ascites and full term pregnancy, this is the first ever case in the world to be reported. Chylous ascites with pregnancy only 5 cases have been reported earlier. And above all, only 20 cases of ovarian lymphangioma are reported in the literature so far. Lymphangioma is usually asymptomatic and unilateral, presenting as an incidental finding during routine gynaecologic procedures. It is made up of aggregates of lymphatic spaces in ovarian stroma and the endothelial cells lining these spaces. The main differential diagnosis is an adenomatoid tumour which can be differentiated from the lymphangioma by immunohistochemical studies. We report this rare lesion in a case of 28 years old primigravida with 37 weeks of gestation with pregnancy induced hypertension with acute distension of abdomen with respiratory distress.
\end{abstract}

Keywords: Lymphangioma, Ovary, Chylous ascites, Pregnancy

\section{INTRODUCTION}

Chylous ascites is an uncommon finding which is due to the presence of thoracic or intestinal lymph in the abdominal cavity. ${ }^{1,2}$ It is usually caused by a chronic disruption of the lymphatic system. Bilateral lymphangioma of the ovary being an extremely rare lesion, with chylous ascites and full term pregnancy, this is the first ever case in the world to be reported. Chylous ascites with pregnancy only 5 cases have been reported earlier. Lymphangioma is a benign lesion of the lymphatic vessels that is characterised by lymphatic proliferation. Lymphangioma of the ovary is extremely rare and only 20 cases have been reported. ${ }^{3,4}$ It is a benign vascular lesion, lined by a single layer of flattened endothelial cells. However, 2 case reports of its malignant counterpart has been reported ${ }^{5}$.Earlier reports suggested lymphangiomas to be neoplastic but it is now believed to be hamartomatous in origin. ${ }^{6,7}$ Most of the lesions are asymptomatic and are usually discovered incidentally during routine gynaecological procedures. Manifestation of ovarian lymphangioma as chylous ascites has also been reported previously in non-pregnant patient. ${ }^{4}$ Lymphangioma may appear as septated cystic lesions on ultrasound imaging. ${ }^{3}$ Despite the benign nature, it is important for clinicians to be aware of its rarity and to consider it in the differential diagnosis of unilateral multicystic lesion of the ovary. We report this rare lesion in 28 years old primigravida with 37 weeks of gestation with pregnancy induced hypertension with bilateral ovarian cystic lymphangioma with chylous ascites.

\section{CASE REPORT}

Twenty eight years old Primigravida presented with 37 weeks of gestation with acute distension of abdomen and respiratory distress. She had 2 antenatal check-up previously but the details were not available. On examination, pulse was $96 / \mathrm{min}$, Blood pressure of 140/90 $\mathrm{mm} \mathrm{Hg}$, Respiratory rate of $26 / \mathrm{min}$. On abdominal examination- abdomen was over distended, tense and stretched out skin, size of the uterus could not be made 
out; fetal heart rate was 146/min on Doppler. On per vaginal examination - OS closed, posterior, uneffaced. On ultrasound examination, massive ascites compressing over the gravid uterus was seen with a single live intrauterine pregnancy corresponding to 35 weeks of gestation was seen. Left ovary was enlarged and was measuring 16x12 cm with multiple cystic lesions of variable size and right ovary measured $5 \times 4 \mathrm{~cm}$ with small cysts. Blood and urine investigations were within normal limits. Patient was taken for emergency caesarean section. Intra operatively 3 litres of chylous fluid was suctioned out and sent for analysis. A live male baby of 2400 grams was delivered which cried immediately after birth. Left ovary was massively enlarged (Figure 1) with multiple cystic components and was removed (Figures 2 and 3). Right ovarian biopsy taken. Both the specimen sent for histopathology. Patient withstood the procedure well. An intra-abdominal drain was kept which was removed on $4^{\text {th }}$ post-operative day. Post-operative period was uneventful and patient was discharged on day 10 after suture removal. Ascitic fluid analysis confirmed its chylous nature and histopathology revealed bilateral ovarian cystic lymphangioma (Figures 4 ).

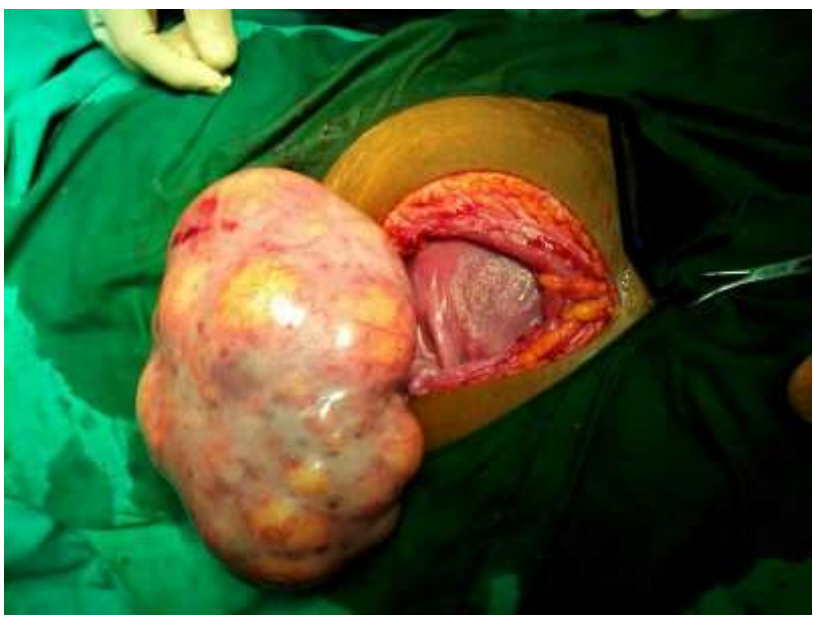

Figure 1: Cut section of left ovarian mass.

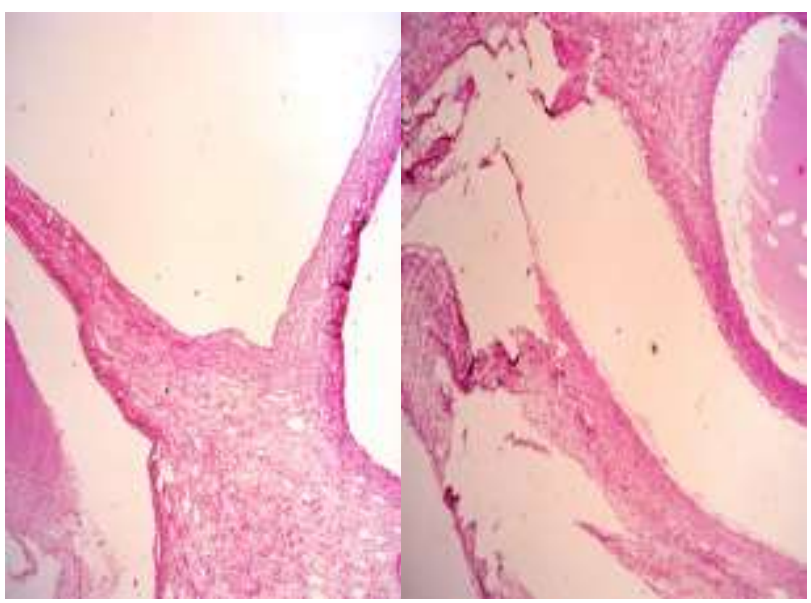

Figure 2: Histopathology suggestive of ovarian lymphangioma.



Figure 3: Left ovarian mass.

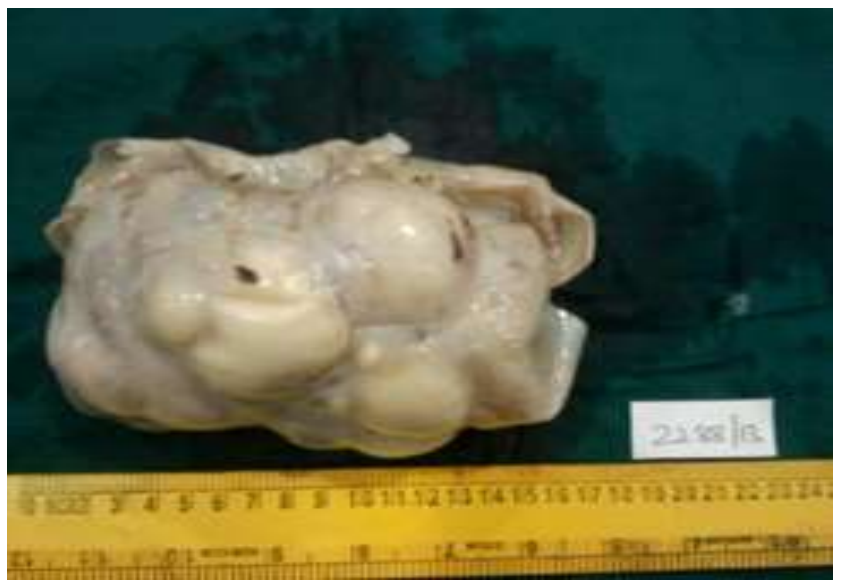

Figure 4: Intra-operative image showing massively enlarged left ovary.

\section{DISCUSSION}

The lymphatic system consists of a network of unidirectional vessels that collects excess fluid from the interstitium, transports it to the regional lymph nodes and ultimately drains to the venous system via the thoracic duct. The lymphatic vessels are seen in all organs except in the brain, anterior chamber of the eye and in systems with rich sinusoidal networks such as bone marrow and spleen. Some authors have suggested that impaired regional lymphatic drainage due to chronic follicular salpingitis or radiation therapy is the cause. ${ }^{8,9}$ Other authors have suggested that they are true neoplasms. Their exact aetiology is still unknown. Some authors suggest that their origin by proliferation by lymphoid nests after inflammation, fibrosis or genetic predisposition, while many believe it as an end result of mechanical pressure, trauma, degeneration of lymph nodes, and disorders of lymphatic vasculature. ${ }^{10-15}$ Most are asymptomatic and are found incidentally. Lymphangiomas are commonly seen in the head, neck and the upper body regions. Intra-abdominal visceral lymphangiomas being very rare mostly are seen in relation to the intestine and the mesentery. ${ }^{14,15}$ 
Lymphangioma involving the female genital organs has been reported in the cervix, uterus, and fallopian tubes and, on rare occasions, the ovary. ${ }^{16,17}$ The first description of lymphangioma of the ovary was published by Kroemer. ${ }^{18}$ Lymphangioma of the epididymis has been reported before. ${ }^{19}$ Lymphangiosarcoma is very rare, although 2 of the 8 cases of ovarian lymphangiomatous lesions reported in the literature may have had a sarcomatous transformation. ${ }^{3,5,19}$ The lesion is mostly unilateral but bilateral lesions have also been reported earlier. ${ }^{10}$ Earlier, lymphangiomas had been considered to be neoplastic in nature and capable of aggressive behaviour. ${ }^{6}$ Lymphangioma of the ovary, following radiation therapy; previously treated for Wilm's tumour during childhood with radiation therapy has also been reported. ${ }^{11}$ A case of ovarian torsion in utero secondary to an ovarian lymphangioma has been reported and laparotomy was performed on the infant after 11 days of life. ${ }^{20}$ A case of ovarian cystic lymphangioma in a 72 year old post-menopausal women which was managed laproscopically has also been reported..$^{21}$ Aristizabal et al reported a case of lymphangioma that rapidly recurred and spread into adjacent and distant peritoneal organs following oophorectomy. ${ }^{15}$ It has been suggested that careful follow up for at least 2 years is needed for patients with lymphangioma of the ovary in order to exclude recurrence. Chylous ascites or chyloperitoneum develops when there is a disruption of the lymphatic system which can occur due to different causes. ${ }^{22}$ The most common causes are abdominal malignancies and cirrhosis which account for more than two-thirds of the cases in developed countries, where infectious diseases are prevalent particularly in developing countries. Chylous ascites is a milky, hazy, intra-abdominal fluid rich in triglyceride. ${ }^{23}$ It is a rare complication during pregnancy. There have been five cases reported and published earlier. These cases occurred and were recognized during pregnancy or after delivery. Three were found as a complication during pregnancy due to pancreatitis and intestinal volvulus and two were nontraumatic, coincidental finding during cesarean section. $^{24-28}$

\section{CONCLUSION}

To the best of our knowledge, this is the first ever case of bilateral ovarian lymphangioma with chylous ascites with term pregnancy ever reported and this is the second case of ovarian lymphangioma with chylous ascites ever reported, first case by Iwasa et al In conclusion, our case highlights the importance of being aware of this rare entity and of considering it in the differential diagnosis in patients found to have multi-cystic lesions of the ovary.

Funding: No funding sources Conflict of interest: None declared Ethical approval: Not required

\section{REFERENCES}

1. Press OW, Press NO, Kaufman SD. Evaluation and management of chylous ascites. Ann Intern Med 1982; 96: 358-364.

2. Cardenas A, Chopra S. Chylous ascites. Am J Gastroenterol 2002; 97: 1896-1900.

3. Singer T, Filmar G, Jormark S, Seckin T, Divon M. Rare case of ovarian cystic lymphangioma. J Minim Invasive Gynecol. 2010; 17:97-9.

4. Iwasa T, Tani A, Miyatani Y, et al. Lymphangioma of the ovary accompanied by chylous ascites. J Obstet Gynaecol Res. 2009; 35:812-5.

5. Rice M, Pearson B, Treadwell WB. Malignant Lymphangioma of ovary. Am J Obstet Gynecol. 1943;45:884-9.

6. Goetsch E. Hygroma colli cysticum and hygroma axillare: Pathologic and clinical study and report of twelve cases. Arch Surg. 1938;36:394.

7. Kurman RJ. Nonspecific tumors of the ovary including mesenchymal tumors and malignant lymphomas. Blaustein's Pathology of Female Genital Tract. Talerman A. edi. 5th Ed, Springer. New York, 2001. Pp. 1044.

8. Evans A, Lytwyn A, Urbach G, Chapman W. Bi lateral lymphangioma of the ovary immunohistochemical characterization. Int J Gynecol Pathol. 1999;18:87-90.

9. Heinig J, Beckmann V, Bialas $\mathrm{T}$, Diallo $\mathrm{R}$. Lymphangioma of the ovary after irradiation due to Wilms tumour in childhood. Eur Obstet Gynaecal Reprod Biol. 2002;103:191-4.

10. Enzinger FM, Weiss SW. Tumor of lymph vessels. In:Gay SM, editor. Soft tissue tumor. St Louis, MO. 1988:614-37.

11. Bonhomme A, Broeders A, Oyen RH, Stas M, De Wever I, Baert AL. Cystic lymphangioma of the retroperitoneum. Clin Radiol. 2001;56:156-8.

12. Hauser H, Mischinger HJ, Beham A, Berger A, Cerwenka H, Razmara J, et al. Cystic retroperitoneal lymphangioma in adults. Eur J Surg Oncol. 1997;23:322-6.

13. Roisman I, Manny J, Fields S, Shiloni E. Intra abdominal lymphangioma. Br J Surg. 1989;76:485-9.

14. Galifer RB, Pous JG, Juskiewenski S, Pasquie M, Gaubert J. Intro-abdominal cystic Lymphangiomas in childhood. Prog Pediatr Surg. 1978;11:173-238.

15. Aristizabal SA, Galindo JH, Davis JR, et al. Lymphangiomas involving the ovary. Report of a case and review of the literature. Lymphology. 1977; 10:219.

16. Logani KB, Agarwal K. Lymphangioma of the ovary. J IndianMed Assoc. 1997;95:146.

17. Siddall RS, Clinton WR. Lymphangioma of the ovary. Am J Obstet Gynecol. 1937;34:306.

18. Kroemer L. Malignant lymphangioma of the ovary. In: Anton G, Viet J, editors. Handbuch der gynak. Weisbaden, Germany: Bergmann; 1908. Pp. 332.

19. Kok KY, Telesinghe PU. Lymphangioma of the epididymis. Singapore Med J. 2002;43:249-50. 
20. Park C, Lee JW, Kim J. Sonographic Findings of Prenatal Torsion of Ovarian Lymphangioma. 2005;33(8):423-3.

21. Naik SA. Rare case of ovarian cystic lymphangioma managed at laparoscopy. J Gynec Endosc Surg. 2011;2:97-100.

22. Weiser AC, Lindgren BW, Ritchey ML, Franco I: Chylous ascites following surgical treatment for Wilms tumor. J Urol. 2003;170:1667-9.

23. Smith EK, Ek E, Croagh D, Spain LA, Farrell S. Acute chylous ascites mimicking acute appendicitis in a patient with pancreatitis. World Journal Gastroenterol. 2009;15:4849-52.

24. Chuang SC, Lee KT, Wang SN, Kuo KK, Chen JS. Hypertriglyceridemia-associated acute pancreatits with chylous ascites in pregnancy. J Formos Med Assoc. 2006;105:583-7.

25. Habek D, Habek JC, Vujic B. Nontraumatic chyloperitoneum in pregnancy. Eur $\mathrm{J}$ Obstet Gynecol. 2005;122:243-51.

26. Liu CJ, Yen CL, Chang JJ, Lee TS, Fan KM. Chylous ascites in acute pancreatitis during pregnancy. Chang Gung Med J. 2001;24:324-8.

27. Kondratev NP. Small intestine volvulus complicated by acute chylous in pregnant woman. Khirurgiia. 1980;2:90-1.

28. Babic I, Tulbah M, Ghourab S. Spontaneous resolution of chylous ascites following delivery: a case report. Journal of Medical Case Reports. 2012;6:187.

Cite this article as: Daddenavar A, Daddenavar V, Patil R. Bilateral ovarian cystic lymphangioma with chylous ascitis in pregnancy - a rare case report with review. Int J Reprod Contracept Obstet Gynecol 2016;5:1633-6. 